\title{
A fly larva (Syrphidae: Ocyptamus) that preys on adult flies
}

\author{
Onanchi Ureña ${ }^{1} \&$ Paul Hanson ${ }^{2 *}$ \\ 1. Escuela de Biología, Universidad de Costa Rica, 2060 San José, Costa Rica; phil_oni@yahoo.fr \\ 2. Escuela de Biología, Universidad de Costa Rica, 2060 San José, Costa Rica; phanson@ biologia.ucr.ac.cr \\ Corresponding author.
}

Received 27-VII-2010. Corrected 05-VIII-2010. Accepted 11-VIII-2010.

\begin{abstract}
Predatory syrphid larvae feed on relatively immobile prey, but here we report the first case (as far as we are aware) of obligatory predation on very mobile prey. Larvae of an undescribed species of Ocyptamus (Diptera: Syrphidae) were found in whitefly (Hemiptera: Aleyrodidae) aggregations on the undersides of citrus leaves. However, instead of preying on the whitefly nymphs (as would be expected), the larvae preyed on adult flies (Diptera) that were attracted to the honeydew. In the laboratory, larvae captured significantly more flies on whitefly infested leaves than on washed leaves, and generally abandoned leaves that lacked whiteflies. Most cases of successful prey capture involved flies that probed the anterior part of the larva's body with its proboscis (as if it were honeydew). The syrphid larva lashed out at the fly and entangled it in sticky oral secretion. The prey did not recover when they were removed from the larva, suggesting that this new predatory species also employs venom to subdue its prey. Although the larvae consumed some honeydew, they were unable to complete their development on this diet. Two parasitoids were reared from Ocyptamus puparia, Proaspicera sp. (Hymenoptera: Figitidae) and Paracarotomus sp. (Hymenoptera: Pteromalidae), both of which are endoparasitic koinobionts. Rev. Biol. Trop. 58 (4): 1157-1163. Epub 2010 December 01.
\end{abstract}

Key words: Aleyrodidae, citrus, Costa Rica, Diptera, honeydew, whitefly.

Flower flies, or hover flies (Diptera: Syrphidae), are very diverse in the Neotropics. The biology of the larval stages is quite variable, but most species of the subfamily Syrphinae are predators of homopterans (Hemiptera) and other small, soft-bodied arthropods that feed on plants, especially those that live in aggregations (Rotheray 1993, Rotheray \& Gilbert 1999). In all predatory Syrphinae, as far as we are aware, the larvae feed on relatively slow-moving prey. Among the best studied species are those that feed on aphids, and these larvae generally lift their prey off the substrate, which may serve to prevent the prey from sending alarm signals to the rest of the colony (Rotheray 1986).

The genus Ocyptamus is an endemic new world taxon consisting of more than 300 species, the vast majority of which are neotropical
(Thompson \& Zumbado 2000). The biology of most species is still unknown, but the available information suggests that feeding behavior is like that of other Syrphinae, although some species are predators of aquatic insects living in bromeliads (Rotheray et al. 2000). Here we report on the biology of the larvae of an undescribed species of Ocyptamus, which were found living among whitefly nymphs (Hemiptera: Aleyrodidae) on the undersides of citrus leaves. Normally one would expect syrphid larvae in this situation to feed on the whitefly nymphs, but to our surprise this was not the case. Instead, we found that the larvae of this Ocyptamus species attacks and subdues adult flies that are attracted to honeydew. Whiteflies feed on phloem sap and excrete honeydew (Byrne et al. 2003), which attracts ants 
(Queiroz \& Oliveira 2001) and other sugarseeking insects.

\section{MATERIALS AND METHODS}

Observations were carried out in the field and laboratory from November 2000 to the beginning of 2002 on the campus of the University of Costa Rica, located in San Pedro de Montes de Oca, at 1100 meters elevation. The syrphid larvae were collected from whiteflyinfested leaves of citrus trees (Citrus). Eggs and larvae were brought to the laboratory for rearing, and the larvae were maintained by feeding them with adult Drosophila melanogaster and D. saltans (Diptera: Drosophilidae). Leaves containing an egg or larva were placed individually in Petri plates $(9 \mathrm{~cm}$ diameter) with filter paper (Whatman) that was kept slightly humid. Adult Drosophila were also placed in the Petri plates and the latter were then sealed with Parafilm ("M", American National $\mathrm{Can}^{\mathrm{TM}}$ ) to minimize contamination with mites and fungi, and to maintain humidity. For all of the experiments third instar Ocyptamus larvae were used. Larvae were filmed in the laboratory with a camera (Sony CCD-TR 3000) and close-ups were done by attaching this camera to a dissecting microscope (Javelin color CCTV, JE-3662RGB). Filming was done in the Smithsonian Tropical Research Institute in the Republic of Panama.

To study the attraction of adult Drosophila to whitefly nymphs and honeydew, two types of leaves were used, with whiteflies and without whiteflies. The latter were washed with distilled water and inspected under a dissecting microscope to ensure the absence of whiteflies. Both types of leaves were placed in Petri plates $(n=7)$ and observations were carried out for one hour; every two minutes the number of flies on each type of leaf was recorded. To study the effect of the presence of whiteflies on the rate of prey capture, each syrphid larva $(n=29)$ was subjected to two treatments in Petri plates: with a whitefly infested leaf and with a clean leaf. Eight adult Drosophila were then released in each Petri plate. Each syrphid larva was subjected to each treatment in a randomized sequence to avoid possible effects between treatments. Larvae spent the previous night without prey and each experiment was filmed for one hour. To examine the possibility that the syrphid larva coats its body with honeydew, a similar experiment to the previous one was carried out. However, in this one, larvae were washed with five drops of water and then placed in Petri plates for $12 \mathrm{hr}$ (the previous night) with or without whitefly nymphs, but without Drosophila prey. Each larva was then placed in a Petri plate with washed leaves and eight adult Drosophila. Again a matched pairs design was utilized, whereby the order of the treatments was randomized for each larva.

The efficiency of prey capture was recorded as the number of successful captures during one hour, divided by the total number of attempted captures (including failed attempts). Successful prey capture was evaluated according to one of the next three different types of predator and prey interaction: 1 - the prey made contact with the middle or posterior part of the syrphid larva with its proboscis; 2 - the prey made contact with the anterior region of the syrphid larva with its proboscis and 3 - the prey walked over the syrphid larva without making contact with its proboscis.

Honeydew from whitefly nymphs was stained with a non-toxic dye (McCormick food color and egg dye) and then fed to the syrphid larvae by allowing the latter to imbibe the colored honeydew through a micropipette. After imbibing the colored honeydew, the syrphid larvae $(n=3)$ were placed with prey to observe whether honeydew was regurgitated during prey capture.

When Ocyptamus larvae strike their prey they liberate a sticky secretion from the mouth, which was analyzed for sugars by means of anisaldehyde-sulfuric acid, which reveals the presence of sugars but not the type of sugar. Larvae were placed with prey under a dissecting microscope and the secretion was collected with a micropipette. Two larvae were used and two samples were taken from each. In addition 
two samples of whitefly honeydew and commercial sucrose were analyzed. The samples were diluted in two drops of ethyl acetate and placed on silica gel plates (Baker-Flex). To run the samples, ethyl hexane-acetate $3: 2,8: 2$, 6:4 and of methanol-acetate $8: 2$ were used. To examine the possibility that Ocyptamus larvae utilize a paralyzing venom, 17 larvae were placed individually in Petri plates with whitefly infested leaves and adult Drosophila. Once the larva trapped its prey, the latter were removed with forceps within one minute of being "bitten" and the reaction of each prey was monitored at 1.5 and $15 \mathrm{~min}$.

Once the Ocyptamus larvae pupated and adults emerged, the latter were fed for a few hours with a solution of honey in water. The Ocyptamus reared in this study is an undescribed species (C. Thompson 2010, pers. comm.) and adult specimens are deposited in the U.S. National Museum, Washington, D.C. The parasitoids reared from Ocyptamus puparia are deposited in the Zoology Museum of the University of Costa Rica.

\section{RESULTS}

Life cycle: Two adult females were observed in the field ovipositing on citrus leaves that harbored whitefly nymphs. In each case the fly hovered near the leaf, landed, probed the leaf with her abdomen and laid an egg. Adult males were not observed in the field. The egg was $0.87 \pm 0.038 \mathrm{~mm}$ long and $0.32 \pm 0.02 \mathrm{~mm}$ wide $(n=6)$. It is white, with sculpturing on the chorion (Fig. 1), as has been reported in other syrphids (Chandler 1968, Gilbert 1986). On two of 14 leaves (28\%) more than one egg was found among the whitefly nymphs, but no more than one larva was ever found on a leaf $(n=41)$. On one occasion a first instar larva was observed feeding on an egg and such cannibalism is apparently common in the subfamily Syrphinae (Chandler 1969, Schneider 1969, Gilbert 1986). On another occasion an unidentified coccinellid (Coleoptera) was observed consuming an egg of Ocyptamus.

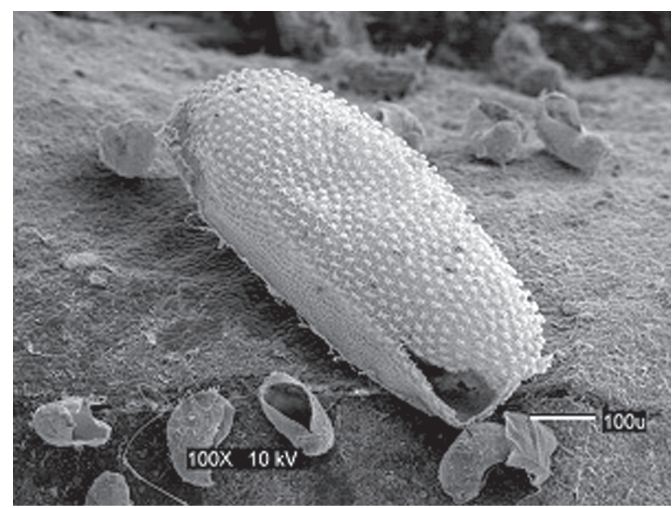

Fig. 1. Egg of Ocyptamus sp.

The larvae eclosed in approximately three days $(n=4)$ and recently eclosed larvae were $0.77 \pm 0.031 \mathrm{~mm}$ in length $(\mathrm{n}=5)$. The first instar larvae are transparent with white globules along the body. In the second instar, the white globules along the body are still visible but the overall color is greenish transparent. In the third instar, the white globules become concentrated in the central portion of the body and are similar to whitefly nymphs in overall appearance, making it somewhat difficult to distinguish the outline of the larva's body (Fig. 2). Of all the larvae collected in the field $(n=41)$, none was found on leaves lacking whitefly nymphs.

Field collected larvae were successfully reared on a diet consisting exclusively of

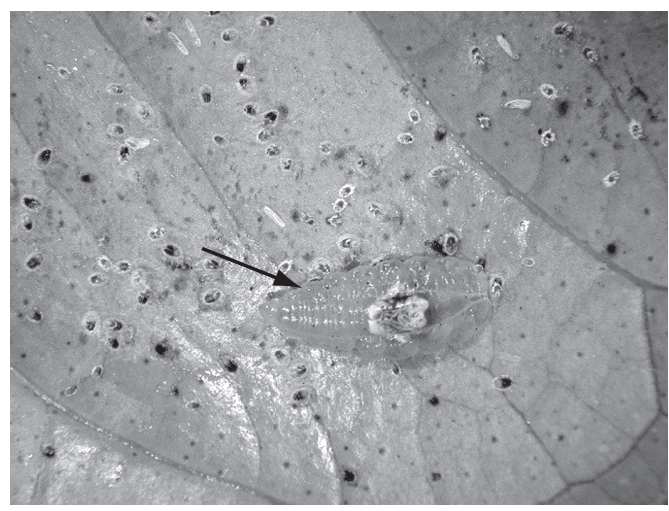

Fig. 2. Third instar larva of Ocyptamus sp. (arrow) with numerous whitefly nymphs (photo by Kenji Nishida). 
adult Drosophila. First and second instar larvae required approximately 4-6hr to consume the prey $(n=2)$, whereas third instar larvae devoured an adult Drosophila much more quickly, in approximately $30 \mathrm{~min} \quad(\mathrm{n}=5)$. In the field they were observed consuming sarcophagids, stratiomyiids and neriids for periods lasting up to four hours. The larvae became inactive for about a day preceding a molt. The duration of the larval stages was $14.3 \pm 0.615$ days $(n=6)$. Larvae of Ocyptamus were never observed feeding on whitefly nymphs in the field or in the laboratory. Attempts to rear them on whitefly nymphs $(\mathrm{n}=2)$ and aphids $(\mathrm{n}=2)$ failed. The larvae occasionally fed on honeydew excreted by the whiteflies, but attempts to rear them exclusively on this diet failed $(n=4)$.

Before pupating the larvae excreted a dark substance. In the field pupae $(n=4)$ were found on green stems of the plant. The pupal period lasted approximately eight days in the laboratory $(n=13)$, and three days before adult emergence eyes, wings and legs were visible through the cuticle. Parasitized pupae were generally darker in color. Two hymenopteran parasitoids were reared from puparia: Proaspicera sp. (Figitidae) and Paracarotomus sp. (Pteromalidae). Since the syrphid larvae were collected in the field and these parasitoids emerged from

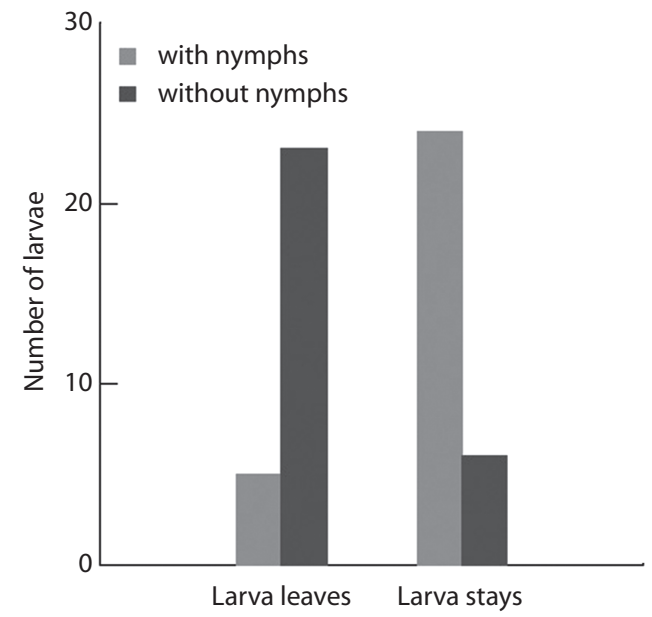

Fig. 3. Number of larvae that abandon and remain on leaves: with and without whitefly nymphs. puparia in the laboratory, these two species can be assumed to be endoparasitic koinobionts. Proaspicera spent 23 days in the puparium $(\mathrm{n}=1)$ and Paracaratomus spent $22.7 \pm 0.33$ days $(n=3)$. Total rate of parasitism was $9.75 \%$ $(n=41)$.

Prey capture: The number of Drosophila present on leaves with whitefly nymphs was significantly greater than the number present on clean leaves. Every two minutes there were an average of 2.25 flies present on leaves with whiteflies versus 0.35 on leaves without whiteflies (student $\mathrm{t}=3.14, \mathrm{p}=0.008$, $\mathrm{n}=14$ ). When an Ocyptamus larva was present on the leaf the difference was nearly significant $(F[1 / 5]=6.45, p=0.052)$. Larvae placed on clean leaves abandoned the leaf and moved around the Petri plate much more frequently than larvae placed on leaves with whitefly nymphs (Fig. 3). The number of prey captured was greater on leaves with whiteflies than on leaves without whiteflies (Fig. 4). However, previous contact with whitefly nymphs had no effect on the average number of prey captured (paired $\mathrm{t}=-1.246, \mathrm{p}=0.24, \mathrm{n}=10$ ). Nonetheless, the average number of Drosophila present on the leaf was significantly greater when larvae had previous contact with whiteflies than when

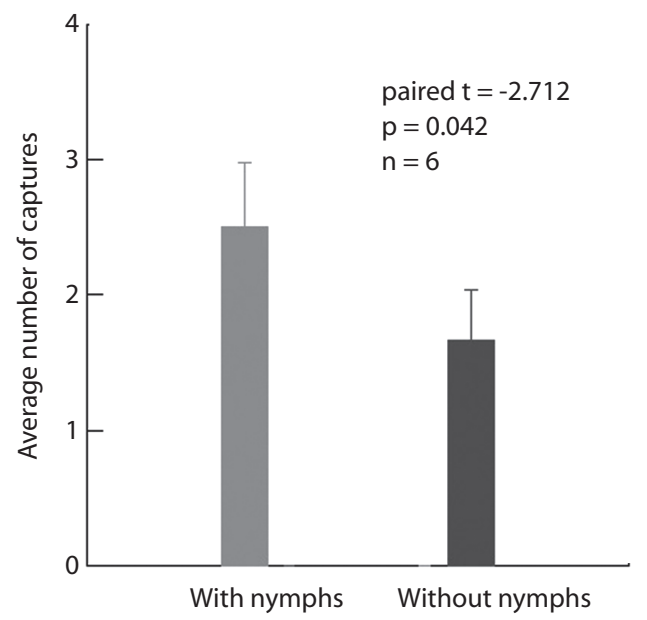

Fig. 4. Average number of prey captured on leaves with and without whitefly nymphs. 
they did not $(\mathrm{F}[1 / 9]=7.109, \mathrm{p}=0.026))$. Seven out of ten larvae provided with Drosophila in the absence of whitefly nymphs died after two days; upon inspecting the leaves on which three larvae survived it was discovered that scale insects (Hemiptera: Coccidae) were present (and evidently had not been removed by prior leaf washing).

Adult Drosophila made contact with the middle and anterior portion of the syrphid larva more frequently than with the posterior portion $\left(\chi^{2}=14.5\right.$, g.l. $\left.=2, \mathrm{p}=0.001\right)$. Prey capture was much more successful when the flies contacted some part of the larva's body with its proboscis than when the fly simply walked rapidly over the larva without extending its proboscis. Moreover, prey capture was greater when Drosophila contacted the anterior portion of the larva's body than when it contacted the middle or posterior portions (Table 1).

During prey capture the larva of Ocyptamus lashes out very rapidly with the anterior end of its body. Third instar larvae captured adult Drosophila in an average of $0.37 \pm 0.04 \mathrm{~s}$ $(\mathrm{n}=12)$. During this process it secretes a sticky substance from its mouth $(n=41)$, which is most evident when capturing large prey. This sticky substance entangles the legs of the prey and greatly reduces its mobility. Upon examining entangled prey with a dissecting microscope and manipulating them with forceps $(n=6)$, the sticky threads appeared to harden with time. When the prey managed to escape $(n=4)$ it still remained on the surface of the leaf with its legs stuck together in such a manner that movement was difficult. The larva feeds by perforating and sucking out the contents of its prey. When finished feeding, the larvae flicked the empty exoskeleton off the leaf with a rapid jerk of its anterior end.

When larvae were fed with colored honeydew, the dye was clearly observed through the larval cuticle in two structures on the sides of the posterior gut. When these larvae were provided with prey, no blue dye was observed in the oral secretion. Nonetheless, the chemical analysis of this secretion tested positive for sugars. In the experiment to determine the possible presence of a paralyzing venom, the Drosophila prey were removed after being "bitten" by Ocyptamus larvae. After one minute, $84 \%$ of the prey $(n=17)$ still moved their legs and wings. After five minutes only $15 \%$ showed movement and after $15 \mathrm{~min}$ all prey were immobile. None of the prey ever recovered.

\section{DISCUSSION}

Since the larvae of Diptera lack legs, it is perhaps not surprising that most predatory dipteran larvae are restricted to capturing immobile or relatively slow-moving prey, such as the immature stages of other insects. Among the few dipteran larvae that capture fast-moving, adult insects are those of Vermileonidae, which construct pitfall traps in the soil (Devetak 2008) and some Keroplatidae, which construct sticky webs (Baker \& Merritt 2003). As far as we are aware, our results provide the first evidence for a syrphid larva feeding in an obligatory manner on very mobile prey, i.e. adult flies. The larvae of this undescribed species of Ocyptamus were

TABLE 1

Rate of prey capture by Ocyptamus in different situations

\begin{tabular}{ccccccc} 
Situation $^{1}$ & \multicolumn{3}{c}{ With nymphs on leaves } & \multicolumn{3}{c}{ Without nymphs on leaves } \\
& Successes & Failures & Success rate & Successes & Failures & Success rate \\
1 & 5 & 12 & $29.4 \%$ & 5 & 31 & $13.9 \%$ \\
2 & 10 & 5 & $66.7 \%$ & 5 & 13 & $27.8 \%$ \\
3 & 0 & 12 & $0 \%$ & 0 & 29 & $0 \%$
\end{tabular}

\footnotetext{
${ }^{1}$ Situation $1=$ prey probes posterior and middle part of predator's body with its proboscis. Situation $2=$ prey probes anterior
} part of predator's body with its proboscis. Situation 3=prey contacts predator's body without probing it with its proboscis. 
unable to survive when provided with nothing but whitefly nymphs or aphids. Although our sample size for this experiment was small, larvae were never observed in the field or in the laboratory feeding on whitefly nymphs. Although it is unknown whether the larvae prey on other insects that are attracted to honeydew (e.g. hymenopterans), in the laboratory a larva was observed consuming an ant. In the absence of prey the larvae appear to be capable of subsisting for a while on honeydew, but are unable to complete their development on this diet.

Our results suggest that the larvae of this Ocyptamus species are dependent upon the presence of honeydew to attract their prey. Moreover, when placed on leaves that had been washed, the larvae wandered around the Petri plate, but stopped wandering if given leaves infested with honeydew. This is an unsurprising result since a larva can only capture prey that comes in contact with its body. Preliminary results suggest that honeydew from soft scale (Coccidae) can serve the same function, but more research is needed to determine the range of sugary substances utilized by Ocyptamus sp. to attract their prey.

Successful prey capture by Ocyptamus depends on the fly probing the anterior region of the larva's body with its proboscis. Flies more frequently probed the anterior and middle portion of the body than the posterior portion, which suggests that the larva cover this portion of its body with a sugary attractant. Sugar was detected in the oral secretions of the larvae but when dyed honeydew was ingested by the larva it was not observed in the oral secretion. Alternatively, the larva may simply use the honeydew from its surroundings. This aspect of its biology requires further study.

When a fly probes the anterior portion of the larva's body, the latter moves its head extremely rapidly to capture the fly and the latter becomes entangled in a sticky oral secretion. Syrphid larvae that prey on honeydewsecreting insects are known to use sticky saliva as a defense mechanism against ants and parasitoids (Gilbert 1986, Rotheray 1986), and to hold prey (Rotheray 1993). The larvae of the
Ocyptamus species studied here nearly always strike their prey (an adult fly) in the head, often in its extended proboscis. Our results strongly suggest that they inject a paralyzing venom since captured flies become immobile and do not recover. In the field, larvae were observed feeding on flies much larger than themselves (e.g. adult sarcophagids) and these prey were not struggling to escape. The only previous report of syrphid larvae using venom to subdue their prey is in aquatic species of Ocyptamus that live in bromeliads, which also attack relatively large-sized prey (Rotheray et al. 2000).

This unique manner of capturing adult flies shown by the larvae of Ocyptamus sp. appears to be an example of aggressive mimicry (Zabka $\&$ Tembrock 1986). The behavior of its prey, adult flies, suggests that they do not detect the presence of the predatory larva and indeed they probe the larva as if it were honeydew. The cryptic coloration of the larva might serve to complement the putative chemical mimicry. It is possible that the unusual behavior of the species studied here evolved from an ancestral behavior of preying on insects that excrete honeydew (as occurs in other Ocyptamus species) but a phylogenetic analysis is required to test this suggestion.

\section{ACKNOWLEDGMENTS}

The first author wishes to thank William Eberhard, Daniel Briceño, Nélida Gómez and William Wcislo for their comments on the thesis (Escuela de Biología, Universidad de Costa Rica) on which this study is based; Vivian Méndez, Patricia Ortiz, Elizabeth Capaldi and Kenji Nishida for their support; Jorge Cevallos for the SEM photos; and Nelly Rivas and Nyree Abad for the sugar analysis carried out at the University of Panamá, Republic of Panama.

\section{RESUMEN}

Las larvas depredadoras de Syrphidae se alimentan de presas relativamente inmóviles, pero aquí reportamos el primer caso (hasta ahora conocido) de la depredación 
obligatoria en presas muy móviles. Se encontraron las larvas de una especie no descrita de Ocyptamus (Diptera: Syrphidae) juntas con ninfas de mosca blanca (Hemiptera: Aleyrodidae) en el envés de las hojas de cítricos. Sin embargo, en vez de alimentarse de las ninfas de mosca blanca (como debería esperarse), las larvas se alimentaron de moscas adultas (Diptera) que fueron atraídas a las excreciones azucaradas de la mosca blanca. En el laboratorio, las larvas capturaron más moscas cuando estaban en hojas con mosca blanca que cuando estaban en hojas lavadas, y generalmente abandonaron las hojas sin mosca blanca. La mayoría de las capturas exitosas de presas ocurrieron cuando la mosca extendió su proboscis y tocó la parte anterior de la larva del sírfido. La larva regurgita hilos pegajosos en el momento de capturar una presa y presas removidas de la larva no recuperaron su movibilidad, lo cual sugiere que el depredador utiliza un veneno para inmovilizar la presa. Aunque las larvas se alimentaron de excreciones azucaradas de mosca blanca, no pudieron completar su desarrollo en esta dieta. Se obtuvieron dos parasitoides de los puparios del sírfido, Proaspicera sp. (Hymenoptera: Figitidae) Paracarotomus sp. (Hymenoptera: Pteromalidae), ambos son koinobiontes endoparasíticos.

Palabras clave: Aleyrodidae, citrus, Costa Rica, Diptera, excreciones azucaradas de homópteros, mosca blanca.

\section{REFERENCES}

Baker, C.H. \& D.J. Merritt. 2003. Life cycle of an Australian glow-worm Arachnocampa flava Harrison (Diptera: Keroplatidae: Arachnocampinae). Austral. Entomol. 30: 45-55.

Byrne, D.N., D.L. Hendrix \& L.H. Williams. 2003. Presence of trehalulose and other oligosaccharides in hemipteran honeydew, particularly Aleyrodidae. Physiol. Entomol. 28: 144-149.

Chandler, A.E.F. 1968. A preliminary key to the eggs of some of the commoner aphidophagous Syrphidae (Diptera) occurring in Britain. T. Roy. Ent. Soc. Lond. 120: 199-218.
Chandler, A.E.F. 1969. Locomotory behaviour of first instar larvae of aphidophagous Syrphidae (Diptera) after contact with aphids. Anim. Behav. 17: 673-678.

Devetak, D. 2008. Substrate particle-preference of wormlion Vermileo vermileo (Diptera: Vermileonidae) larvae and their interaction with antlions. Eur. J. Entomol. 105: 631-635.

Gilbert, F.S. 1986. Hoverflies. Naturalists' Handbook 5. Cambridge, Cambridge, England.

Queiroz, J.M. \& P.S. Oliveira. 2001. Tending ants protect honeydew-producing whiteflies (Homoptera: Aleyrodidae). Environ. Entomol. 30: 295-297.

Rotheray, G.E. 1986. Colour, shape and defense in aphidophagous syrphid larvae (Diptera). Zool. J. Linn. Soc. Lond. 88: 201-216.

Rotheray, G.E. 1993. Colour guide to hoverfly larvae (Diptera: Syrphidae). Dipterists Digest No. 9. Whiteley, Sheffield, England.

Rotheray, G.E. \& F.C. Gilbert. 1999. Phylogeny of Palaearctic Syrphidae (Diptera): Evidence from larval stages. Zool. J. Linn. Soc. Lond.127: 1-112.

Rotheray, G.E., M. Zumbado, E.G. Hancock \& F.C. Thompson. 2000. Remarkable aquatic predators in the genus Ocyptamus (Diptera, Syrphidae). Stud. Dipterol. 7: 385-398.

Schneider, F. 1969. Bionomics and physiology of aphidophagous Syrphidae. Annu. Rev. Entomol. 14: 103124.

Thompson, F.C. \& M. Zumbado. 2000. Flower flies of the subgenus Ocyptamus (Mimocalla Hull) (Diptera: Syrphidae). P. Entomol. Soc. Wash. 102: 773-793.

Zabka, H. \& G. Tembrock. 1986. Mimicry and crypsis - A behavioral approach to classification. Behav. Process. 13: 159-176. 